\section{Cadmium elicits alterations in mitochondrial morphology and functionality in C3H10T1/2Cl8 mouse fibroblast cell}

\author{
Monica Oldani, ${ }^{1}$ Chiara Milani, ${ }^{1}$ \\ Federico Gaboardi,2 Marta Manzoni, ${ }^{3}$ \\ Anna M. Villa, ${ }^{1}$ Federico M. Stefanini, ${ }^{4}$ \\ Pasquale Melchioretto, ${ }^{2}$ \\ Eugenio Monti, ${ }^{3}$ Matilde Forcella, ${ }^{1}$ \\ Chiara Urani,2,5 Paola Fusi1,5 \\ 1Dipartimento di Biotecnologie e \\ Bioscienze, Università degli Studi di \\ Milano-Bicocca, Milano; ${ }^{2}$ Dipartimento \\ di Scienze dell'Ambiente e della Terra, \\ Università degli Studi di Milano- \\ Bicocca, Milano; ${ }^{3}$ Dipartimento di \\ Medicina Molecolare e Traslazionale, \\ Università degli Studi di Brescia, \\ Brescia; ${ }^{4}$ Dipartimento di Statistica, \\ Informatica, Applicazioni, Università \\ degli Studi di Firenze, Firenze; \\ 5Integrated Models for Prevention and \\ Protection in Environmental and \\ Occupational Health (MISTRAL) \\ University Research Center, Pisa, Italy
}

\begin{abstract}
In this work we exploit the widely used, well known in vitro Cell Transformation Assay (CTA), which allows following healthy cells transformation into a malignant phenotype, to understand the early metabolic deregulation and events in cadmium-induced carcinogenesis.
\end{abstract}

\section{Introduction}

Cadmium is a widespread carcinogen. ${ }^{1}$ We previously showed that the administration of low $\mathrm{CdCl}_{2}$ doses for 24 hours to healthy $\mathrm{C} 3 \mathrm{H} 10 \mathrm{~T} 1 / 2 \mathrm{Cl} 8$ mouse embryonic fibroblast cell line at the beginning of Cell Transformation Assay (CTA), up regulates genes involved in metal scavenging and antioxidant defense, like metallothioneines, Glutathione S-transferases and heat shock proteins. ${ }^{2}$ Still, although most cells thrive normally in the following weeks, malignancy is triggered by $\mathrm{CdCl} 2$ and leads to the appearance of foci of transformed cells at the end of the CTA. 3,4

\section{Materials and Methods}

Respiratory metabolism was investigated through Seahorse Agilent assays, while oxidative stress level was assessed through fluorescent probes; DNA damage was evaluated by Comet assay, and mitochondrial morphology was analyzed in confocal microscopy.

\section{Results}

Results show that the initial response to $\mathrm{CdCl}_{2}$ involves mitochondria rearrangement into a perinuclear network. However, SOD1 and SOD2 activities are inhibited, leading to increased superoxide anion level, which in turn causes DNA strand breaks. From the metabolic point of view, cells increase their glycolytic flux, while all extra NADH produced is still efficiently reoxidized by mitochondria.

\section{Discussion and Conclusions}

Our results confirm previously shown response against cadmium toxicity; new data about glycolytic increase and mitochondrial rearrangements suggest pathways leading to cell transformation.

\section{References?}

1. Jarup L, Akesson A. Current status of cadmium as an environmental health problem. Toxicol Appl Pharmacol 2009;238:201-8.

2. Callegaro G, Forcella M, Melchioretto $\mathrm{P}$, et al. Toxicogenomics applied to in vitro cell transformation assay reveals mechanisms of early response to cadmium. Toxicol Vitro 2018;48:232-43.

3. Urani C, Stefanini FM, Bussinelli L, et al. Image analysis and automatic classification of transformed foci. J Microsc 2009;234:269-79.
Correspondence: Monica Oldani, Dipartimento di Biotecnologie e Bioscienze, Università degli Studi di Milano-Bicocca, Piazza della Scienza 2, 20126, Milano.

Tel.: 0264483409

E-mail: m.oldani12@campus.unimib.it

Key words: Cadmium carcinogenesis; cell metabolism; DNA damage; mitochondria; ROS.

Acknowledgments: This work was supported by the University of Florence ("Progetto Dipartimenti di Eccellenza" - MIUR, Italy, 2018-2022, FMS); by the University of Milano-Bicocca (grants 2017-ATE-0335 to CU and 2017- ATE-0273 to PF).

Disclosures: The authors declare that they have no known competing financial interests or personal relationships that could have appeared to influence the work reported in this paper.

Conference presentation: This paper was presented at the Third Centro 3R Annual Meeting - L'era delle 3R: modelli in silico, in vitro e in vivo per promuovere la ricerca traslazionale 30 September - 1 October 2021, Evento online organizzato dal Politecnico di Torino.

Received for publication: 9 July 2021.

Accepted for publication: 7 September 2021.

This work is licensed under a Creative Commons Attribution NonCommercial 4.0 License (CC BY-NC 4.0).

(C) Copyright: the Author(s), 2021

Licensee PAGEPress, Italy

Biomedical Science and Engineering 2021; 4(s1):185 doi:10.4081/bse.2021.185

4. Forcella M, Callegaro G, Melchioretto $\mathrm{P}$, et al. Cadmium-transformed cells in the in vitro cell transformation assay reveal different proliferative behaviours and activated pathways. Toxicol Vitro 2016;36:71-80.

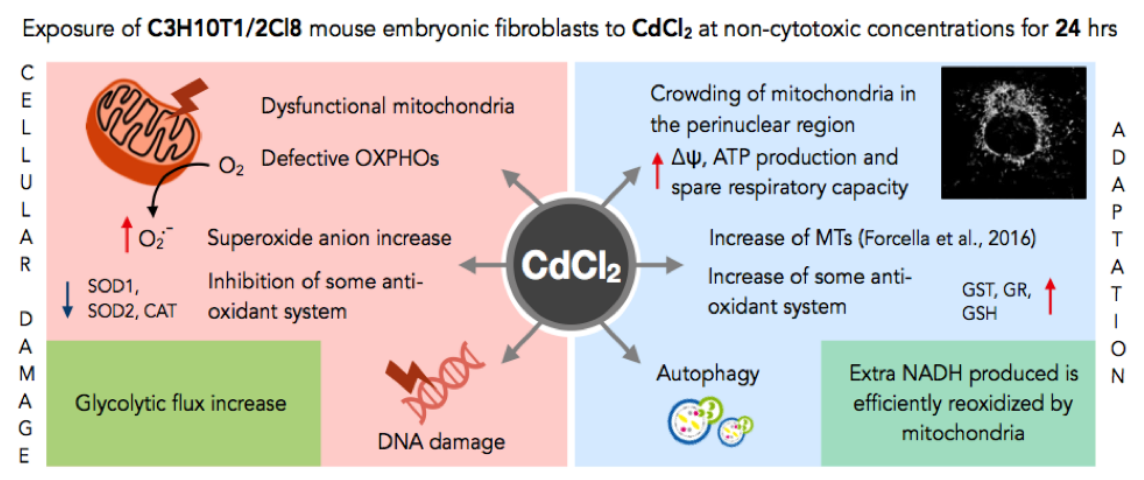

Figure 1. Summary of the results. 